\section{BMJ Paediatrics Open}

\title{
Palivizumab reimbursement criteria and neonatal RSV hospitalisation: a regional retrospective review
}

\author{
Valeria Belleudi, ${ }^{1}$ Federico Marchetti, ${ }^{2}$ Marco Finocchietti, ${ }^{1}$ Marina Davoli, ${ }^{1}$ \\ Antonio Addis (iD ${ }^{1}$
}

To cite: Belleudi V, Marchetti F, Finocchietti M, et al. Palivizumab reimbursement criteria and neonatal RSV hospitalisation: a regional retrospective review. BMJ Paediatrics Open 2021;5:e000985. doi:10.1136/ bmjpo-2020-000985

Received 10 December 2020 Accepted 14 February 2021
Check for updates

\section{(c) Author(s) (or their} employer(s)) 2021. Re-use permitted under CC BY-NC. No commercial re-use. See rights and permissions. Published by BMJ.

'Department of Epidemiology, Regional Health Service, Azienda Sanitaria Locale Roma 1, Roma, Italy

${ }^{2}$ Pediatrics, AUSL Ravenna, Ravenna, Italy

Correspondence to Dr Antonio Addis; agmaddis@ gmail.com

\section{ABSTRACT}

In Italy, reimbursement restrictions regarding palivizumab prophylaxis approved in 2016 have been revoked in 2017, restoring use in infants with Gestational Age (GA) >29 weeks. Respiratory Syncytial Virus (RSV) hospitalisations and prevalence of palivizumab use in infants aged $<6$ months during five seasons (2014-2019), were considered according to different GA. Although RSV hospitalisations rate showed no significant changes, during different seasons in all GA, lower prevalence of palivizumab use in 2016 ( $0.8 \%$ vs $0.3 \%)$, returned to a higher level following the revoke of restrictions. Changes in reimbursement criteria were not associated with neonatal RSV hospitalisations rate but with a significant impact on palivizumab use.

\section{INTRODUCTION}

Since its introduction onto the market, palivizumab has been associated with an intense debate regarding the best target population where to be used. ${ }^{1}$ Such controversy has resulted from conflicting data on efficacy in different risk categories and due to its expense. $^{2}$

In Italy, following publication of American Academy of Pediatrics' (AAP) guideline in $2014,{ }^{3}$ prescribers and decision-makers tried to define a new strategy for the identification of paediatric patients for whom palivizumab prophylaxis is more effective. The review of all data on efficacy and safety convinced in 2016 the Italian Medicines Agency (AIFA) to restrict reimbursement to infant born at Gestational Age (GA) $\leq 29$ weeks.

However, after considerable pressure by the Italian Society of Neonatology and patient associations, in October 2017 AIFA decided to revoke the new limitations, eliminating the reimbursement restrictions for infants born at GA 30 to 35 weeks.

We wished to ascertain, using real-world data, the impact of these reimbursement limitations over time (2014-2019) updating our previous analysis ${ }^{4}$ on Respiratory Syncytial Virus (RSV) hospitalisation prevalence and drug consumption. On this new study, we focused on infants $<6$ months during RSV seasons, analysing all results according to different GAs.

\section{METHODS}

Specifically, we considered three periods: two seasons before the implementation of the 2016 limitations (2014/2015 to 2015/2016), one season after the approval of limitations (2016/2017) and two seasons following the revoke of such reimbursement limitations (2017/2018 to 2018/2019). A comparison between different periods among RSV hospitalisation rate and prevalence of palivizumab use in infants aged $<6$ months according to GA was performed. We are not able to have laboratory confirmation of RSV diagnosis and so, during the same period, we measured also Other Respiratory Virus (ORV) infectionbased hospitalisations.

In particular, data were extracted from three main sources: the certificate of delivery care reporting information on mother and baby characteristics at birth, such as GA; the drug claims registry collecting information on drug prescriptions reimbursed by the healthcare system and dispensed by private or public pharmacies; the hospital information system collecting information on all hospital discharges registered in regional hospitals.

\section{RESULTS}

We identified 218275 infants aged $<6$ months during the five (2014-2019) epidemic RSVinfection seasons. In the same periods 6304 hospitalisations due to infection by respiratory virus, for infant aged $<6$ months were recorded. Of these 2348 (37.2\%), were cases of RSV infection (ICD-9-CM 079.6; 466.11; 480.1).

RSV infection-based hospitalisation rates in the periods before, during and after 


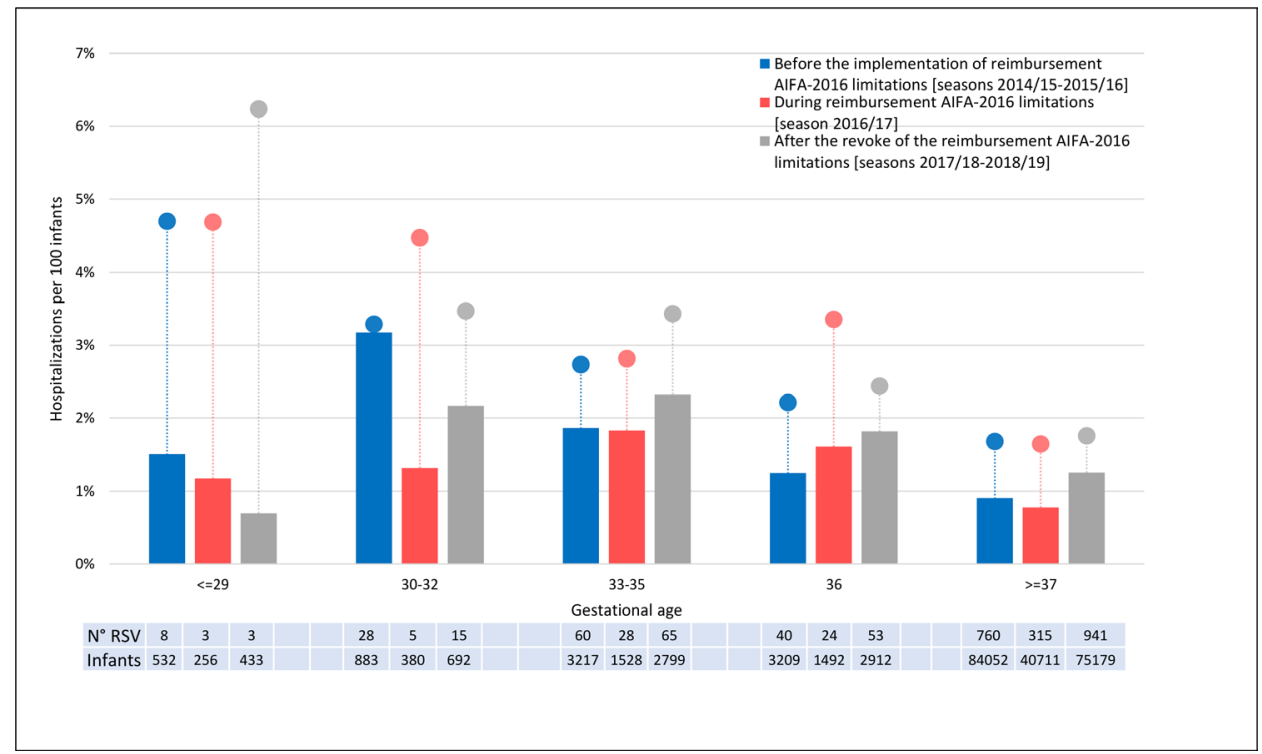

Figure 1 Hospitalisations per 100 infants for infection by the RSV (bar plot) and ORV (circle plot) according to gestational age before, during and after implementation/revoke of reimbursement AIFA-2016 limitations. AIFA, Italian Medicines Agency; ORV,Other Respiratory Virus; RSV, Respiratory Syncytial Virus.

AIFA-2016 limitations were $0.98 \%$ (95\% CI $0.91 \%$ to $1.04 \%), 0.85 \%$ (95\% CI $0.76 \%$ to $0.93 \%)$ and $1.34(95 \%$ CI $1.24 \%$ to $1.39 \%$ ), respectively. Following the introduction of 2016 reimbursement restrictions, no increase in the number of hospitalisations in infants between 30 to 35 weeks of GA was observed (figure 1). During the same epidemic seasons, we did not see any particular variation in ORV.

In the season following the approve of reimbursement limitations, a reduction in the prevalence of palivizumab use was noted $(-0.5 \%)$, in particular, more than 1800 prescriptions of palivizumab were avoided (figure 2). After the revoke of such limitations, palivizumab prescriptions returned or even increased the levels observed before October 2016 with different distribution between GAs.

\section{DISCUSSION}

This new study completed our previous analysis on the impact of the reimbursement decision by the Italian National Health Service based on international guidelines. ${ }^{4}$ However, this new analysis showed how the turn-u regulatory decision was associated with a new increase on palivizumab prescriptions, still without any impact on RSV hospitalisation rate for children aged $<6$ months.

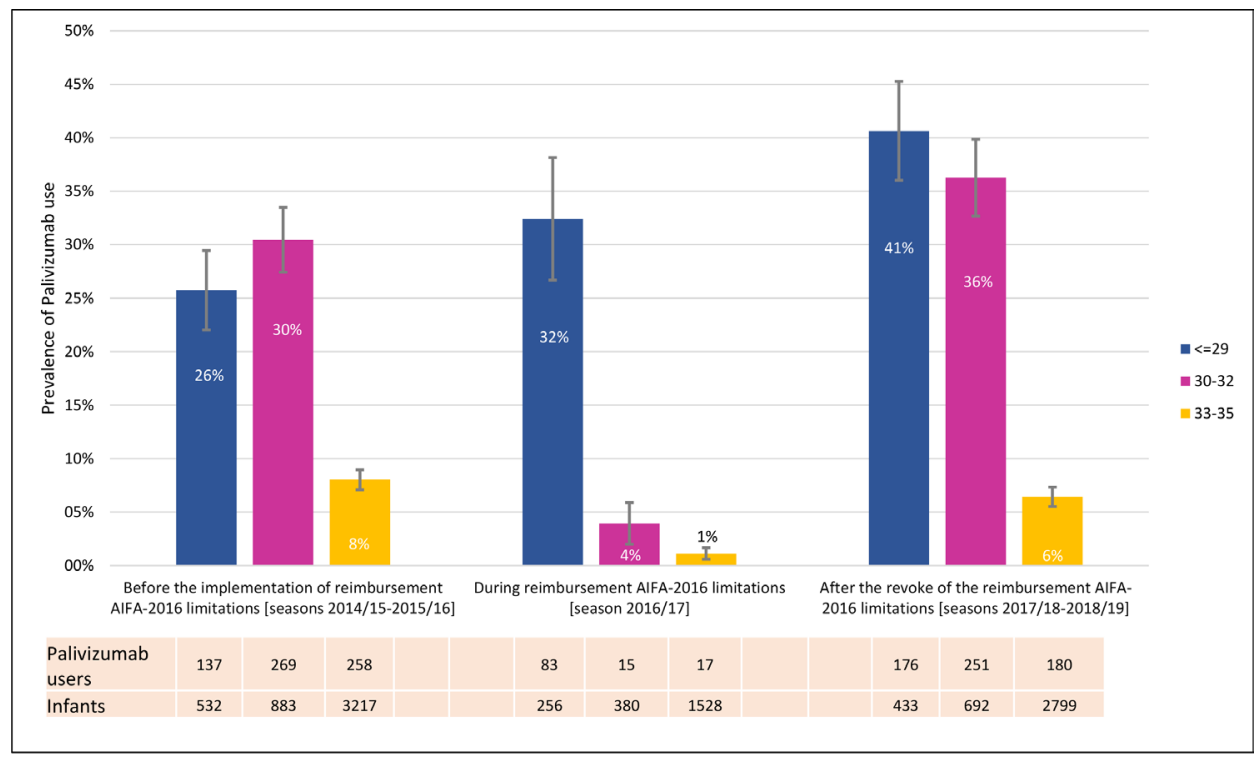

Note. We observed a mean of three prescriptions of palivizumab for infant for season.

Figure 2 Prevalence of palivizumab use according to gestational age before, during and after implementation/revoke of reimbursement AIFA-2016 limitations. AIFA, Italian Medicines Agency. 
Our results are limited to one single Italian region (Lazio). However, when we project these data up to the national level, the prevalence reduction on palivizumab prescriptions $(-0.5 \%)$, following the 2016 reimbursement limitations, correspond to a potential nationwide saving of $€ 5.5 \mathrm{million} / \mathrm{season}$. On the other hands, the new increase registered in the seasons 2018/2019 corresponds to an increase in palivizumab expenditures of 5.7 million/season.

It is also worthy to note that after the revoke of AIFA's reimbursement limitations the prevalence of palivizumab use in infant $\leq 29 \mathrm{GA}$ is higher than that observed in the period before the regulatory restrictions ( $41 \%$ vs $26 \%$ ).

Several limitations of our study must be mentioned, study does not consider seasonal variation in the RSV intensity, we were not able to have laboratory confirmation of RSV and we do not have track of palivizumab use during hospitalisation. However, our data are consistent with other studies ${ }^{25}$ where the implementation of the 2014 AAP guidelines did not increase RSV hospitalisations or disease severity among children hospitalised for RSV.

In conclusions, according to our analysis, changes in reimbursement criteria were not associated on differences in RSV hospitalisation rate for children aged $<6$ months but with significant impact on palivizumab use.

Contributors VB, FM and AA conceptualised, designed the study and drafted the manuscript. MF performed the data analysis. MD contributed to the study design and reviewed the manuscript. All authors approved the final manuscript as submitted.
Funding The authors have not declared a specific grant for this research from any funding agency in the public, commercial or not-for-profit sectors.

Competing interests None declared.

Patient and public involvement Patients and/or the public were not involved in the design, or conduct, or reporting, or dissemination plans of this research.

Patient consent for publication Not required.

Provenance and peer review Not commissioned; externally peer reviewed.

Open access This is an open access article distributed in accordance with the Creative Commons Attribution Non Commercial (CC BY-NC 4.0) license, which permits others to distribute, remix, adapt, build upon this work non-commercially, and license their derivative works on different terms, provided the original work is properly cited, appropriate credit is given, any changes made indicated, and the use is non-commercial. See: http://creativecommons.org/licenses/by-nc/4.0/.

ORCID iD

Antonio Addis http://orcid.org/0000-0003-0962-9959

\section{REFERENCES}

1 Pignotti MS, Carmela Leo M, Pugi A, et al. Consensus conference on the appropriateness of palivizumab prophylaxis in respiratory syncytial virus disease. Pediatr Pulmonol 2016;51:1088-96.

2 Farber HJ, Buckwold FJ, Lachman B, et al. Observed effectiveness of Palivizumab for 29-36-Week gestation infants. Pediatrics 2016;138:e20160627.

3 American Academy of Pediatrics Committee on Infectious Diseases, American Academy of Pediatrics Bronchiolitis Guidelines Committee. Updated guidance for palivizumab prophylaxis among infants and young children at increased risk of hospitalization for respiratory syncytial virus infection. Pediatrics 2014;134:e620-38.

4 Belleudi V, Trotta F, Pinnarelli L, et al. Neonatal outcomes following new reimbursement limitations on palivizumab in Italy. Arch Dis Child 2018;103:1163-7.

5 Zembles TN, Bushee GM, Willoughby RE. Impact of American Academy of Pediatrics Palivizumab guidance for children $\geq 29$ and $<35$ weeks of gestational age. J Pediatr 2019;209:125-9. 